\title{
T. ROEPER
}

\section{WATCHING NOUNPHRASES EMERGE}

\author{
Seeking Compositionality
}

\subsection{QUESTIONS*}

How does a child project the myriad semantic and syntactic properties of Nounphrases? We will argue that there is a tremendously intricate process required to capture the varieties of possible "reference" that confront the child. At various points non-target options are taken from UG that are consistent with syntactic/semantic defaults. Here are a few questions linked to what children say:

1) a. Why do children say "I want cookie" instead of "a cookie"? Or why does a child answer "towel" instead of "a towel" when asked, "What do you need to wash?"

b. Why do children say "yes" to the question "Does a dog have tails?"? Or why does a child refer to his parents as "husbands and wives"?

c. Why do children say "yes" to the question "Mary's bike is broken. Is John riding the bike?" (a different bike)? Why does a child say "the" in this situation: [ 3 dogs, 2 cats on a fence: one dog falls off] "What fell off the fence?" "The dog?"

These examples are at the level of subtlety that motivates many modern theories, particularly in semantics. It is one thesis of this essay that children, at every moment, make subtle distinctions of interpretation like these examples imply and seek to map them onto grammar. Most syntactic acquisition theories vastly understate the semantic distinctions for which children seek a grammatical representation.

\section{T. Roper, Watching Nounphrases Emerge; Seeking} Compositionality. (C)2003 Kluwer Academic Publishers. Printed in the Netherlands. 
Our theory develops a theory of Minimal Default Grammar (MDG):

$\mathrm{MDG}=$ the Initial State projected from UG

MDG contains: Nodes that are universal (basic form of CP,IP,VP,NP) in a hierarchical relation.

A classic example of a Default projection is a phrase like "Me want" which often occurs in children's grammars, but which adults never use.

We will propose Defaults at three levels of NP:

$\mathrm{N}=$ Kind ("want cookie")

$\mathrm{NP}=$ Predicate ("Joshua home")

DP $=$ Proper Name/deixis (Johnny, that)

These claims reflect the fact that children begin with specific DP's: names $(\mathrm{John}=\mathrm{DP})$, pronouns $($ that $=\mathrm{DP})$, and non-specific bare nouns $($ cookie $=\mathrm{N})$ with no articles. Then children pursue a series of hypotheses about possible forms of specificity that are linked (in part) to a fixation of the article system in a syntactic tree. Above N lies NP. NP has a Spec which we argue has an anaphoric link that allows what is called a predicate reading for words like home. As we show below, anaphoric home appears very early and therefore we suggest that it represents a Default projection.

Between NP and DP come a variety of nodes (see below) that, for instance, permit Degree phrases and guarantee Agreement and are notably absent in early phases of grammar. Their hierarchical order is (by hypothesis) fixed in UG but not every one is present in every grammar, and so the child needs evidence to determine which ones are present in his grammar.

The MDG theory leads naturally to a theory of Multiple Grammars (Roeper (1999), Yang (2003), Chomsky (2001)). The theory assumes that grammars are not completely resolved, but allow lexically limited domains where other grammars exist (for instance in Latin, Greek, and Anglo-Saxon morphology which are all present in English). One of the grammars that remains is the MDG itself. The existence of Headline Grammar is a common example of where adult language uses Default structures and resembles children's language.

\subsection{Compositionality}


How does a child compose syntactic structures into semantic ones? Our goal will be to maintain an allegiance to the data from children and begin with a less formal notion of Child Compositionality which we expect will eventually meet semantic theories. ${ }^{1}$ We assume the following broad principle:

2) Nodes in a tree are linked to semantic distinctions.

\subsection{SYNTACTIC AND SEMANTIC PERSPECTIVES}

Syntax: To orient our approach, consider at one extreme the concept of autonomy of syntax, which was part of the original model of generative grammar (Chomsky (1955)). Under this conception a child might learn the entire syntax of a grammar from the radio without ever assigning meaning to a structure. No stepwise compositionality is required for adult or child.

Semantics: From the semantic tradition, a Fregean approach to compositionality is explicated in Heim and Kratzer (1998), where higher nodes are strictly composed of the contents of lower ones.

3) Locality: Semantic interpretation rules are local: the denotation of any non-terminal node is computed from the denotation of its daughter nodes.

And they add Frege's conjecture:

4) Semantic composition is Function Application

This approach will naturally capture phrases where each element has an independent denotation:

5) eat raisin

But more complex forms of composition are needed to capture phrases where a functional element, without an independent denotation, occur:

6) the hat

Heim and Kratzer argue that if one denotation has no value, then a false presupposition is present, which then requires inclusion of a contextual variable. Thus the interpretation is more complex. 
Integrated Accounts: Modern syntactic structures have become increasingly sensitive to semantic distinctions. Cinque (1999) advocates 62 different Adverb positions, each capturing refined semantics. ${ }^{2}$ The range of possibilities is highly constrained because the Functional Categories in effect subcategorize each other: a verb carries the potential for certain kinds of adverbs.

A recent semantic account can be found in the work of Morzyki (2003) who argues that the syntactic nodes are part of what undergoes semantic composition. For instance, an adverb, remarkably, combines with a Degree node to produce a reading of intensification in an AP like:

$$
\begin{aligned}
& \text { DP }[\text { Deg }[\text { AP }[N P \\
& \text { a. this is a remarkably big tree } \\
& \text { b. }=/=* \text { Remarkably this is a big tree }
\end{aligned}
$$

The reading in (a) is not possible for the adverb in any other position (b). Therefore, he argues that the adverb combines with a Feature in the Degree Phrase to produce the degree interpretation of the adverb. Only just before the adjective is the intensification of Degree a possible reading. A Degree Phrase is an example of the distinctions that the child must seek between a DP and an NP node.

Fixed Hierarchy: Our view is that UG does provide a fixed hierarchy of Functional Categories, but that not all grammars instantiate every node in this hierarchy. Not all the possible adverb categories are independently represented, nor is there an Agreement node for adjectives if they do not agree (as in English). Therefore the acquisition challenge is for the child to determine both the content of elements to be combined and exactly what node dominates them. The errors children make in word-order never involve an error in the hierarchy of FC's. We never see children misplace articles: *apple the.

\subsection{Child Evidence}

In fact, children do exhibit expressions like "eat raisin" before "the hat" and therefore the compositional rules that combine words with separate denotations does seem to precede those where a contextual variable must be included. Therefore, prima facie, the semantic theory mirrors an important part of the acquisition process. Moreover, young children show knowledge of just the kinds of adverb composition that Morzyki discusses with the adverb really:

8) Adjectival degree intensifier: 


\begin{tabular}{ll} 
Shem, $2 ; 8.3$ & "It's really heavy." \\
Nina, 2;9.13 & "That was really funny." \\
Nina, 2;9.26 & "Cause you're really tired." \\
Verbal modifier: & \\
Nina, 3;2.12 & "Yeah, really she didn't." \\
Adam, $3 ; 4.18$ & "Really I didn't." \\
\hline
\end{tabular}

These facts and arguments point toward the idea, not far from common sense, that we need a real conception of how semantic composition figures into the acquisition process.

Now, keeping a steady eye on what the data tells us, we can ask: how much of the path of composition can we see? A great deal more careful experimentation will be needed before it is completely clear, but first let us try intuitively to grasp what the act of composition might look like.

\subsection{Compositional Implications of Merge}

What happens when a child hears two nouns, like doll and house:

9)

$$
\begin{aligned}
\text { Assume: known word }+ \text { known word } & =>\text { composed compound } \\
\text { doll } & \text { house }
\end{aligned}
$$

This seems like common sense, but a close look shows that a number of other steps are possible: A child could make three different steps:

10) idiom: no analysis conjunction: doll and house composition: Modifier and Head

Phrases as Words: If the child recognized the two parts, doll and house morphologically, then the idiomatic analysis would itself call for dropping a compositional analysis, and treating it as a single word. Were this the child's first assumption - make any sequence into a single word if possible---many erroneous compounds should arise. Imagine a parent who hands a child a spoon and says "eat rice" and the child understands eatrice = spoon and says "where my eatrice?" We find amazingly few such errors.

Conjunctions: Were the child to assume that a sequence of words were linked as

conjunctions, then we predict the false conclusion that two objects are implied:

11) "dollhouse" = doll and house 
Conjunctions are notoriously rare in children's utterances. We do not have

$$
\begin{aligned}
& \text { "Mommydaddy" } \\
& \text { "spoonfork" } \\
& \text { "hatcoat," }
\end{aligned}
$$

which would be the utterances we would expect if the child were pursuing simple conjunction as a basis for initial word combinations. Therefore we conclude that the child's first analysis identifies a Head and adds something to it.

$$
\text { Merge to Head: } \mathrm{X}+\text { Head }
$$

This analysis entails the semantic differentiation of a Head. Is the Merged X, added by a rule of semantic composition or just syntactic analysis?

A look at the grammar of compounds provides a clue from the adult grammar. In a series of papers originating in Snyder (1995) on how English children acquire productive compounds and how French children never project productive compounds (Roeper, Snyder, Hiramatsu (2000); Roeper and Snyder (2003)), we realized the importance of Namiki (1994):

There are no three-term idioms.

That is, we may have many two-term idioms:

$$
\text { turncoat, fatcat, footloose, slapdash }
$$

but a three-term compound has some compositional analysis:

$$
\text { turncoat brigade [brigade }+ \text { turncoat] }
$$

Based on this claim, Snyder examined the input to children and found that children who produce novel, compositional two-term compounds ("animal cup", "ribbon hat", "BigBird book") are exposed to three-term compounds from adults ("Christmas tree cookie", "peanut butter sandwich" "baby doll napkin," "nursery school book").

In other words, it appears that compositionality must apply when Merge of a Noun applies twice (a suggestion of B. Partee (pc) (circa1976)):

17) Recursion entails compositionality. 
We argue that children know this principle and seek recursive structures to differentiate lexical idioms from productive rules by requiring that recursive structures submit to compositional analysis. An important corollary for acquisition is a point of non-compositionality:

18) Merge: No compositional relation is required for an analysis of Merge.

Where hierarchy is present, recursive Merge must have applied, therefore a compositional decision is entailed (see Roeper and Snyder (2003)):

19) Claim: Hierarchical structure requires a compositional decision.

Therefore it is plausible to argue that children carry out a morphological analysis:

$$
\text { word }+\mathrm{X}
$$

In essence, children carry forth the operation of Merge, or decompose it without a necessary compositional output. So far, we have an autonomous syntax.

$$
\begin{aligned}
& \text { 21)a. } \quad \begin{array}{c}
\text { word } \\
/ \quad \backslash \\
\text { word affix }
\end{array}
\end{aligned}
$$

However, once again, we cannot have a mystery $\mathrm{x}$ and mystery $\mathrm{y}$ at the same time:

$$
\begin{array}{cc}
\text { b. } & * * \text { word }+ \\
\mathrm{X} & \text { word } \\
/ & \backslash \\
\text { word } & \mathrm{Y}
\end{array}
$$

because recursion requires compositionality. This is a strong claim, and it is possible that there are exceptions. This argument arrives at what is seen as almost "common sense" for the acquisition of morphology. It is an old observation that children misidentify morphemes when they initially recognize them. Slobin (1973) claims:

22) New morphemes first take old functions. 
Slobin observes that morphemes are added without meaning change for gender in Russian:

$$
\text { verb }+ \text { fem }
$$

This is treated as either masculine or feminine. In English, the -ed is added without a clear intension of past reference, but rather continuing the present. The most straightforward suggestion is that in all languages,

24) New morphemes at first take no function.

In other words, this evidence points toward our claim that the Primary Linguistic Data problem forces an initial moment of non-compositional analysis. We can assign a minimal structure to two elements without a) knowing what one of them means, and b) consequently not knowing what the combination means. ${ }^{3}$

\subsection{Compositionality Predictions}

The recursive compositionality requirement has an immediate implication for acquisition theory, a Compositionality Filter:

25) Compositionality eliminates all non-compositional material.

This forces the child to eliminate most of what he first hears because he cannot make sense of it. Note, paradoxically, that the child might in fact "understand" the sentence but still not enter it into his grammar revision machine. A child who looks at a bottle of milk and hears a parent say:

"Will you please finish your milk?"

may be pragmatically able to see exactly what is meant. Nevertheless, the sentence contains all sorts of things beyond his grammar, and therefore is rejected as an input to grammar change. A series of first order predictions are available from this analysis. First,

27) No two morphemes should be acquired without the first Merge being assigned a meaning.

For instance, German involves both Tense and Agreement morphemes. It has been argued that each may appear without a clear meaning (which, of course, does not guarantee that it has no meaning): 


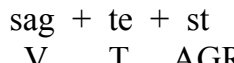

However it has never been claimed to my knowledge that the AGR appears before the Tense receives a meaning.

Second, we predict that articles may appear without meaning. Matthewson and Schaeffer (2000) reports that $20 \%$ of Adam's first definite articles do not have a clear antecedent. This evidence is compatible with the idea that the expletive the initially has no meaning.

\subsection{Acquisition Model for DP}

We will now project the model of NP/DP acquisition that we regard as an idealization of the real process, which we expect to be far more refined. One of our goals is to avoid understating the true intricacy of the grammar to be acquired. Therefore we cast our net wide at first and imagine the largest range of distinct possibilities that a child may confront (still surely too small). Consider this array of discernibly different meanings that NPs can have (we shall discuss them in greater detail below).
a. Bare Noun $=$ kind (want cookie)
b. NP = predicate with anaphoric control (go home)
c. NP generic (I like cats)
d. NP existential (cats are in the yard)
e. NP member of a set (see a dog)
f. NP member of an introduced set (not English)
(There are three dogs. The dog is big)
g. NP expletive definite (I have the ability to do this)
h. DP Part-whole Reference
i. DP Point of View Link (John has four dogs. He thinks the best is the worst.)
j. DP Discourse familiar object (I have a hat. The hat is green.)
k. DP Unique object focal stress: (did he get THE bike)
1. DP Culturally familiar object (where is the sun)

A full exploration of these distinctions and how their acquisition reflects upon semantic theories will require many years of work. In principle each of these forms could be marked with special morphology (and may be in other languages). If we conceive of syntactic projections as a bundle of Features that in turn may represent a distinct semantic formula, then we might expect that each one would project a distinct syntactic node. We imagine a range of NP non-specific projections and DP specific projections. The projetion 
system might look like this, reflecting our hypothesis that there is a progression between Non-specific and Specific.
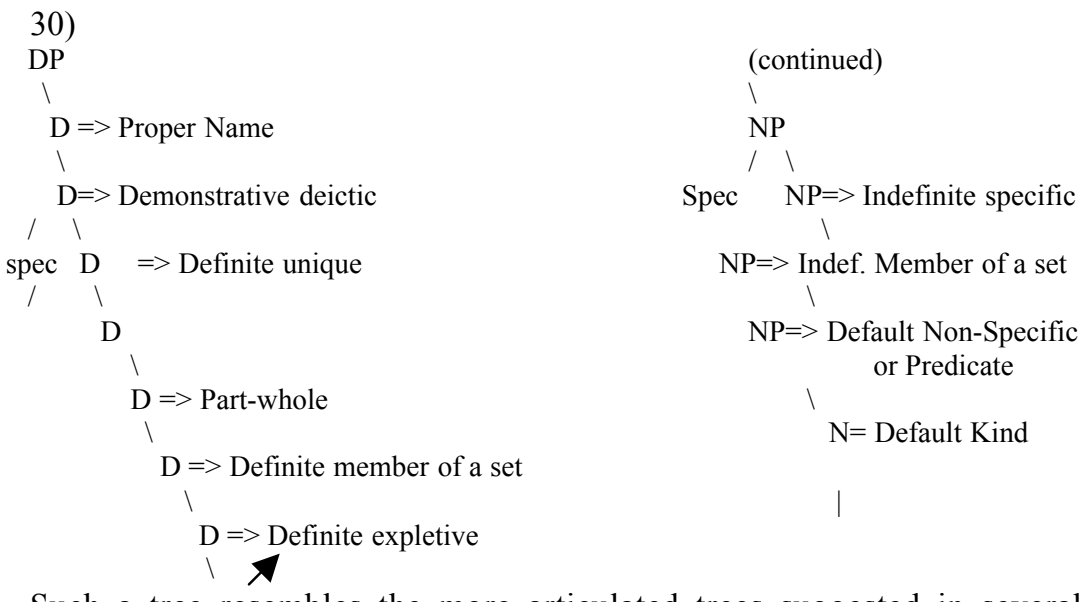

Such a tree resembles the more articulated trees suggested in several theories: 1) Categorial Grammar (Drozd (1993)), 2) Minimalist Grammars without Node labels (Collins (1997,2001), 3) Cinque's proposals (1999) for 62 semantically distinguishable Adverb nodes, and 4) Articulated trees in which DP contains Number, Agreement, Adjective, Gender, Case, and Degree nodes (See Moore (in prep). If we add these to those proposed above, the child would need to locate and instantiate at least 16 different nodes within the DP.

This rough sketch of a tree would be motivated by the notion that increasing specificity adds information and the idea that the child moves roughly from lower to higher nodes. What is missing is exactly what semantic properties would motivate each node. We take the acquisition sequence itself as a first suggestion about what increasing complexity should capture.

\subsection{BARENOUN=KIND}

A child's first utterances are the most linguistically opaque. It is extremely difficult to know just what information the words carry and how much is supplied by inference. If a parent walks into a teenage party and says "Beer!" an entire mindset may be implied, but it is not actually mapped onto that word, rather the word is interpreted according to the situation. The same is true when a small child says "milk". Similarly, older disordered children persist with bare nouns (Schaeffer (2001), Leonard (in press)). We argue that the first stage reflects the notion of Kind, primarily to differentiate the bare noun from the meaning of definite reference. 
The notion of Kind is a traditional one and it reflects the idea that one should not attribute definite reference if it is not present---though people commonly do say the child deleted the in the expression "want cookie", although the intentional verb (want) itself suggests the notion of Kind.

There are modern theories that reduce or replace the notion of Kind (Carlson (1977), and Dayal (1999)) with the notion of Property, for instance, van Geenhoven (1997). ${ }^{4}$ This discussion reaches beyond what the acquisition data reveals. One can simply impose one theory or another upon the data whose origins are outside of acquisition, but that provides no insight unless some clear prediction is made to distinguish our concept (we can call it Child-Kind (Ch-Kind)) to indicate that the acquisition evidence may be compatible with more than one perspective. Nevertheless, two factors incline us to favor the traditional notion of Kind:

i) The notion of Property is broader and includes many other constructions. (It applies to the predicate constructions and pertains to our discussion of NPs and words like home below.).

ii) The notion of Kind reflects the task of partitioning the world into sets from different perspectives. If one asks about the Kind of a car, one might ask if it is a sedan, SUV, station wagon, convertible, or one might ask if it is a Ford, Buick, or Pontiac. The notion of Kind aims at a different question. (Suggested to me by G. Carlson (pc)).

It is certainly true that some finer information involving properties separates one Kind from another (ex. tigers from lions). Such information must be used by the child to differentiate classes, which may at first fail when a child calls cows "dogs." It is possible that the notion of a Property functions as a trigger to a larger concept of Kind. It could thus have a special role to a play in a conception of a Language Acquisition Device, which is not identical to its role in grammar.

\subsection{Expletive Articles}

What information does a child's first use of articles carry? There are several possibilities. Schaeffer and Matthewson have pointed out that children seem to use articles incorrectly without a prior reference. Marinis (2000) points out that Determiners undergo Spreading in early Greek (ex. the big the yellow the house) where the Determiner does not have a compositional reading for each adjective (See also Eisenbeiss (2000)). Carlson (this volume) makes the interesting suggestion that Form/Meaning mismatches are 
helpful to the child in acquisition, which in general seems very likely. For instance, articles appear to function as empty expletives in constructions.

All the victims went to the hospital

where they could in fact go to different hospitals. Such a form/content mismatch could be seen to trigger a syntactic node that would then be home to a number of semantic constructs. We are not sure exactly what expletives entail, but our approach would suggest that they do have meaning, albeit a less specific one. The language has hundreds of examples like: John showed the ability, the audacity, the acumen, the capacity where no prior referent is entailed. Moreover, children show no difficulty in using expletive NP's like: (I'll show you) the way /(I have) the idea/ (Here's) the plan/ (what's) the difference. A brief search for the way revealed these cases:

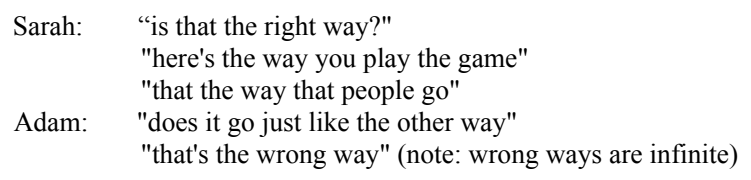

In many instances, children seem to be using a generic concept (ex. the hospital). Evidently, just as we predict, children do not seem to stumble in the slightest over this kind of expletive definite article.

In experimental work, deVilliers and Roeper (1995) and Baauw (2000) showed that these expletives were not barriers to extraction in cases like:

$$
\text { How did John make the decision to wash himself =>how-wash }
$$

and they showed an interaction with binding theory as well. deVilliers and Roeper argue that extraction is consistent with an analysis of expletive Determiner as an NP and not a DP (see home evidence below).

The emergence of expletive articles follows our prediction: less specific interpretations emerge very early, although they are often ungrammatical in the adult grammar.

\subsection{Reference and Sets}

Our broad proposal is that the child moves from Ch-Kind to indefinites and gradually to unique discourse referent. The next stage involves selecting a member of a set. We are able to discern the presence of sets in three different situations:

a) indefinite (I want a dog) 
b) specific indefinite (I want a specific dog)

c) member of a mentioned set (John has 3 hats. He is wearing the biggest hat.)

A great deal of research has addressed how children comprehend indefinites and definites (from Maratsos (1971), Krämer (2000), Avrutin (1999)). Matthewson and Schaeffer (2000) and Matthewson, Bryant, and Roeper (2001) provided evidence that Adam used definites for nonintroduced nouns, and that children were able to use the definite article when it was a member of a set, but not as a unique item. In Salish the discourse "John took a book from the shelf, and then Bill took the book" allows Bill to take a different book, as long as some book has been mentioned.

Precisely this meaning is possible isalish (Matthewson (1998)). They showed that 4-5 yr old children would allow this reading for a) but not b):

Mary has a broken bike.

a) Did Billy ride the bike (he is on a different bike.) $=>$ yes

b) Did Billy ride it $=>$ no

TheSalish definite is less specific and therefore on the path from the most general reference, Ch-Kind, to the most specific, Unique Referent DP (the) ${ }^{5}$

Finally, Schafer and deVilliers (2000) found a similar response with Smith College students. When contrastive sets were present, a definite was chosen for a member of a set:

Three ducks and two dogs were walking across a bridge. One of the animals fell off the bridge and said "Quack". Guess which? or What was it?

While 70\% gave "a duck" as an answer 30\% said "the duck". This suggests that this may remain as a residual grammatical option in adult English as well.

By contrast, we do not believe that the Unique Referent option would constitute a stage of acquisition in an Asian language without articles. It is not "impossible" without a DP because, as Brun and Avrutin (2001) show, it is possible to define specificity by movement rather than by morphology. It is simply not a natural stage in the way that non-specificity is a natural stage because of Default Economy representations.

In sum, children do not randomly explore other grammars: there is a fundamental asymmetry in the acquisition of grammars that reflects a UG division:

A. Some grammars have rich Determiner Systems (overt DP) 
The DP itself, we argue, is projected by Specificity and therefore does not require an article and can house Proper Names. Because the child prefers minimal structure, it will seek to connect overt determiners with non-specific NP's if possible. Therefore the acquisition of determiner rich DP grammars will pass through an NP-only phase, but no NP-only grammars will pass through a phase of projecting DP's. ${ }^{6}$ We predict that children will fail to recognize markers of specificity and treat them as non-specific. ${ }^{7}$

\subsection{NP Defaults}

Although Longobardi (1994) and others (e.g. Baauw (2000) argue for a universal DP, deHoop (1992) has argued for a distinction between Strong and Weak NP's, and Chomsky (1998) has explicitly connected the specific/non-specific distinction to NP/DP. ${ }^{8}$

Our concept of NP's reflects discussions in which it is claimed that an NP is a predicate that carries a property. In Romance, it is common to find bare nouns predicated of a subject:

$$
\text { John is a fool }=\text { John is fool }
$$

English has many instances of bare nouns, though often in larger phrases:
a) I pronounce you man and wife
b) He came, gun in hand
c) Make war against king and country
d) The president stayed on message, off television, on radio...

These constitute a neglected, but very real, corner of English in which we find a Romance grammar. The construction either states an equivalence between subject and predicate or there is implicit control: gun in hand $=\underline{\text { his }}$ gun in his hand, or at home $=$ at his home. ${ }^{9}$

We argue that this kind of control requires an NP that is available as a Default to the child, for which we now provide an overview of theoretical evidence. ${ }^{10}$ First the crucial distinction between $\mathrm{N}$ and NP can be seen in these two sentences:

39) a. John likes singing at home

b. John likes home-singing

In (a) John sings at his own home, but in (b) it can be anyone's home. Thus the $\mathrm{N}$ is incorporated but not the NP, which retains a "controlled" reading: 
40)

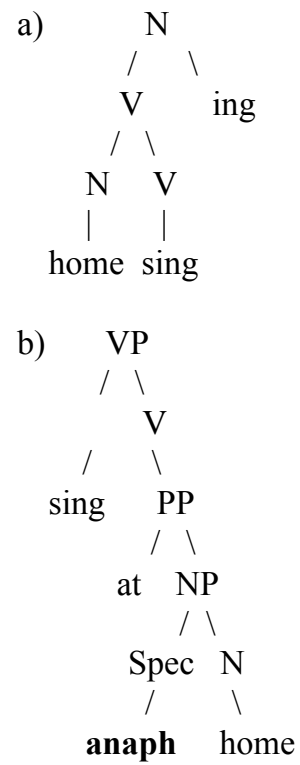

In general, the word home is an NP like many others which is "controlled" in the sense that it is linked to the subject and distributes (everyone went home $=$ different homes). We capture the control property of NP, but not N, by arguing that the NP has a Spec position that contains a hidden Anaphor that is co-indexed with the subject. If it is an anaphor, then it immediately predicts obedience to Principle A of the binding theory (clause-boundedness). This very prediction is the subject of the experiment from Perez and Roeper (1999).

Our earliest evidence in the two-word stage, in fact, suggests that children are able to grasp the anaphoric control reading which we associate with NP and not $\mathrm{N}$ (see below). In each instance, the child has either subject or speaker control, but not an undifferentiated KIND interpretation.

Table 1. Two Word Interpretation

\begin{tabular}{|l|c|}
\hline $\begin{array}{l}\text { Speaker oriented } \\
\text { (Adam's home) }\end{array}$ & $\begin{array}{c}\text { *ADA: Cromer home } \\
\text { *MOT: Cromer's at } \\
\text { your [!!] } \\
\text { home }\end{array}$ \\
\hline
\end{tabular}




\begin{tabular}{|c|c|}
\hline $\begin{array}{l}\text { Speaker oriented } \\
\text { (Adam's home) }\end{array}$ & $\begin{array}{l}\text { *ADA: bike home } \\
\text { *MOT: bike is home. } \\
\text { *MOT: yes. }\end{array}$ \\
\hline $\begin{array}{l}\text { Subject oriented } \\
\text { (Man's home) }\end{array}$ & $\begin{array}{cc}\text { *ADA: } & \text { Man tractor } \\
& \text { drive tractor } \\
& \text { over dere } \\
& \text { home . } \\
\text { *MOT: Yes \# man } \\
\text { driving } \\
\text { tractor over } \\
\text { there. }\end{array}$ \\
\hline $\begin{array}{l}\text { Subject oriented } \\
\text { (Joshua's home) }\end{array}$ & $\begin{array}{r}\text { *ADA: Jowha home } \\
\text { *MOT: Joshua's at his } \\
{[! ! !] \text { home }}\end{array}$ \\
\hline
\end{tabular}

Although two-word utterances are hard to interpret, the following experiment shows that children understand the difference between the controlled NP form (home) and uncontrolled DP form (his home).

In a pilot experiment Blumenfeld (1999)) there is evidence that children will make this distinction in the 6-8yr range where the context allows both:

a. He gave her cookies made at home

b. He gave her home-made cookies

\section{Prompt: Where were the cookies made?}

Bare nouns: $100 \%$ of responses 'at his house.'

Compounds: $12 \%$ responded 'at his house.'

Majority of responses: $60 \%$ 'at the bakery' (or similar)

This evidence contributes to the claim that children are sensitive to the N/NP distinction, although it needs to be replicated with younger children (see also Burns and Soja (1997) who show sensitivity to the NP/DP distinction). At the syntactic level, we have argued that there is an Anaphoric element in the Spec position linked to the Subject (or possibly to the Speaker), because home obeys Principle A like other anaphors (see experiment below). Obligatory control is blocked with an indefinite in the Spec or if a DP is present:

$$
\text { John went to a home/ John went to the home }
$$

The anaphoric properties which we link to Spec-NP (blocked by compound incorporation) can best be seen with quantifiers: 
44) Everybody went home.

for every $\mathrm{x}, \underline{\mathrm{x}}$ a person, $\underline{\mathrm{x}}$ goes to [ $\underline{\mathrm{x}}$ home]. interpretation is more strict than narrow scope

$$
\text { Everybody walks to a home }
$$

narrow scope: Every $\mathrm{x}, \mathrm{x}$ a person, There is a $\mathrm{y}, \mathrm{y}$ a home $[\mathrm{x}$ walks to $y$ ] (no restrictions on selection of $y$ )

$$
\text { Everybody walks to a different home }
$$

( $\mathrm{y}$ is different for each $\mathrm{x}$ )

There are a variety of diagnostic contexts that support this NP analysis pragmatically and syntactically.

47) Diagnostics (see Perez and Roeper (1999)):

1. This bound interpretation is stable and not sensitive to context

a. John lost the audience's interest. (=disjoint)

b. John lost interest. (=John's interest)

c. The audience was enthralled, but as John's voice turned to a monotone, John lost interest. (antipragmatic $=$ still John's interest)

2. $\mathrm{NP}$ is incompatible with restrictive relatives \& restrictive adjectives

a. Ellen visits a beautiful home/*Ellen visits beautiful

home

b. *Ellen visits home that sits near the lake

3. NP exhibits local binding: Home is subject to principle B (Jackendoff et al 1993).

a. John told Bill to work on vacation (=on Bill's vacation)

b.John told Bill to work on his vacation=free (John's,

Bill's, etc.)

4. It obeys C-command.

c. Peter's fiancee went home (the fiancee's home, not Peter's)

5. NP allows extraction where it is blocked by DP.

a. How does John like $t$ [DP the advice *t from his mother]? $=>$ 'very much', i.e., 'how does he like it?'

Cannot be interpreted as 'how is the

advice?' 
b. How does John like [NP advice $t$ from his mother] ? $=>$ 'very much', i.e., 'how does he like it?' $=>$ 'with no ulterior motives', i.e., 'how is the

advice?'

Thus a wide variety of evidence supports this distinction between NP and DP.

\subsection{Home Experiment (Perez and Roeper (1999))}

Stories were constructed to test distributed interpretation and local binding. They are anti-pragmatic in one condition in terms of the question in which children reject an invitation to go to one person's home and go to their own instead

\section{One-Clause Story}

The sheep lives in the barn, the dog lives in the doghouse and the chickens live in the chicken coup. Grover lives in the house, and he loves to play with his animal friends. Some days they play outside, other days they play at Grover's house. Today they played outside until it started to rain. Grover said: 'Lets play at my house for a little longer.'
Target sentence:
a. Everybody went home.
Prompt:
b. Everybody went to his home.
c. Can you show me?

(49)

Table 2. Possible responses to One Clause stories
Distributed Response
Deictic Response
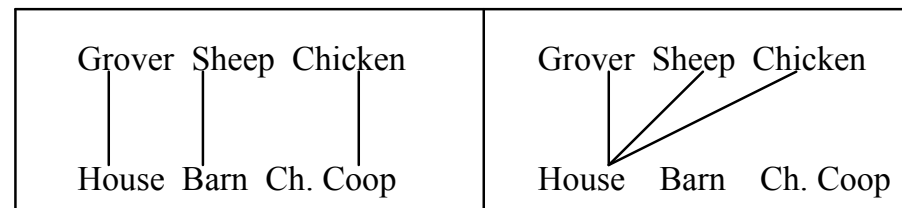

In the two-clause, we are examining whether children obey the Principle A restriction for Anaphors, effectively not allowing "home" to link to "everybody," which is outside the clause:

\section{Two-Clause Story}

The Next day, each animal invited the Lion King to come play at his village. It is getting late, so he does not know if he can. 
Target sentence:

a. Everybody hoped the Lion King would go home, and he did.

b. Everybody hoped the Lion King would go to his home, and he did.

Prompt: c. Can you show me what the Lion King did?

Table 3. Possible responses to two-clause stories

Distributed Response

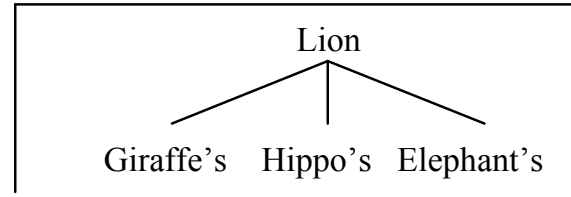

Long distance
Single Response

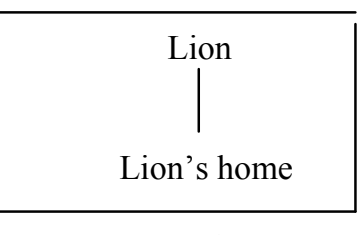

Local

Table 4. The results comparing the two experiments show strongly that the children take distributed responses and obey binding conditions

$\%$ distributed responses

$$
\begin{array}{ll}
\begin{array}{ll}
\text { Experiment } 1 \text { (1 clause) } & \text { Experiment 2 (2clause) } \\
\text { bare } \mathrm{N} & \text { bare } \mathrm{N}
\end{array}
\end{array}
$$

3-4 years

4-5 years

5-6 years

88.9

Adults

These results are compatible with the view that the anaphorically bound NP is available as a Default, and it is consistent with the naturalistic data (Joshua home) cited above for even younger children.

\subsection{DP PROPERTIES}

We can put our theory to a fairly extreme test. We have proposed two fundamental Default projections and a semantic interpretation for each:

Default DP $=>$ Proper Name with Unique Antecedent Default NP $=>$ Member of a set or a Kind

A subtle experiment by Romero and Bock puts these two possibilities in competition to see whether either or both will be selected by children. The 
concept of a Default means that the options remain available to older children. The experiment is built around the use of a Definite Determiner to allow a temporal displacement.

\subsection{Temporal Nouns}

Musan (1995) showed that nouns can be time-independent, if they are not in an expletive environment:

$$
\begin{aligned}
& \text { DP: Time-Independent: } \\
& \text { a. Some professors were radical in the sixties } \\
& \text { =those who are professors now } \\
& \text { Bare Noun: TIME- DEPENDENT } \\
& \text { b. There were radical professors in the sixties } \\
& \text { =those who were radical professors then }
\end{aligned}
$$

These examples show that articles can enable a referential displacement that is contradicted by the current context. For a child to master them, they must not only understand that definiteness creates a link to an entity introduced in the discourse, but that the truth of the phrase may be defined exclusively in the earlier context. ${ }^{11}$

While such sentences may seem unusual, they are certainly a part of the daily life of the child. They will hear from teachers things like:

"Good morning. Isn't it nice that all the sick children are well again?"

Or they might hear on a playing field about children who were injured the previous week, but are now recovered: "It is good that all the injured children are playing again"

\subsection{The Temporal Noun Experiment}

12 stories with pictures were created with 121 questions, counter-balanced, of the following kind and given to 29 children, ages: 3.2-5.6:

Story: "It's warm and these mice are playing in their favorite swimming hole. See this mouse? He's playing on a swing. And this one is hopping from stone to stone. This mouse is splashing in the water. This one is playing in the waterfall. And see this one? Look! He's eating a piece of cheese. They are all enjoying the cool spray of the waterfall. Later in the afternoon, the mice go to a field. The sun is shining. See how bright the sun is? After a while, the mice in the field get very hot. See this mouse. He's sweating. This one is giggling.; he always giggles when he is hot. And this one is so hot he can't move." 
The same mice are cool when they are swimming, but become hot by hiking. The bare noun hot mice should allow no time shift, while the hot mice allows reference to the later hiking state. These are the Adult Responses, assuming Specificity in the DP, and non-specificity for the Adjective+Noun:

54) a. were the hot mice in the swimming hole? YES

b. were there hot mice in the swimming hole? NO

c. are the hot mice in the swimming hole? YES

d. are there hot mice in the swimming hole? NO

SINGLE TIME PATTERN (= default NP, no Specificity)
a. were the hot mice in the swimming hole? NO
b. were there hot mice in the swimming hole? NO
c. are the hot mice in the swimming hole? NO
d. are there hot mice in the swimming hole? NO

NAME PATTERN (=default DP= all are Proper Names)
a. were the hot mice in the swimming hole? YES
b. were there hot mice in the swimming hole? YES
c. are the hot mice in the swimming hole? YES
d. are there hot mice in the swimming hole? YES

Results are linked to a Preponderant "yes" or "no" (see Romero and Bock for details). They found three patterns without strong age variation, but with trends.

They found 12 children who gave us the Adult yes/no variation (BareNoun $=$ non-specific/Determiner $=$ Specific), who on the whole were older. Two children who gave the opposite interpretations (Bare Noun $=$ Specific, Determiner $=$ Non-specific), and they were very young. Their answers could be close to guessing.

The other two major groups were those who consistently took a NAME interpretation for both cases, and those who took a Non-specific "single time" interpretation. That is, they would answer:

57) Were the hot mice in the swimming hole?

with "No because they were cool". 
These results are more impressive because we regard the stories as (unavoidably) pragmatically imperfect. For instance, one could still be hot for awhile in the cool pool before cooling took effect. We take this to explain some of the variation that was found. Nonetheless there are very clear groups that fit into the Name $=\mathrm{DP}$, and the Non-specific $=\mathrm{NP}$ which we take to be the semantic Default, and therefore is construed as referring to the single, present time of the question, ignoring the article.

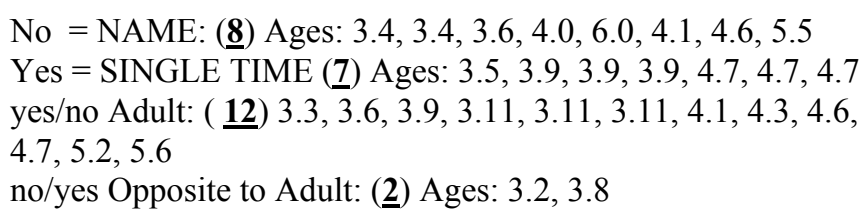

Let us address these results with a series of questions:

1. Why would the child not associate Specificity immediately with DP the? ${ }^{12}$ We argue precisely that NP without definite determiner is the preference for economic representations: it involves less structure and constitutes both a syntactic and semantic Default. ${ }^{13}$

2. Why would some of the children do the opposite and take every reference to be a Name? Our results suggest the DP (Proper Name) is also a Default that is available to them.

Why3does the child not get the definite and indefinite articles right immediately? There is an intricate variety of possible sets and it is not immediately clear what sort each grammar has. ${ }^{14}$ Preference is for the NP non-specific because it involves less structure.

In conclusion, we have seen the appearance of Default syntactic/semantic representations in very subtle environments.

\subsection{PARTIAL CONCLUSIONS}

Our theoretical model and acquisition data are far from painting a complete picture. We remain uncertain what steps are taken by children and we expect the ultimate DP map to be heavily influenced by their decisions. Moreover, we cannot be completely sure that children all follow the same path, nor do we see clearly how Defaults reappear and how Multiple Grammars connect. Nevertheless we have shown that children's grammar operates with great 
semantic subtlety at all times. We have argued that there is clear and strong evidence that children:

a) move from less specific to more specific,

b) that this path mirrors the tree from N to NP to DP,

c) that defaults play a prominent role in grammar, and

d) that the concept of compositionality is natural and should play a central role.

We have also sought to articulate what it means for semantics to meet acquisition. In part, one accepts UG as a statement of defaults and innate structure. However beyond that the best method is to seek definitions of core concepts that reflect acquisition data and theory rather than to impose existing semantic theories. In this way, semantic theory can benefit from the insights that subtle steps in language development reveal about semantic formulations.

\subsection{Multiple Grammars and Non-uniform responses}

Acquisition analysis often abstracts away from age differences because they are difficult to explain, and it abstracts away from percentage responses for the same reason. A natural explanation for percentage responses is that children "revert to the default" some of the time, but at other times they exhibit a more adult grammar. We take the Default form seriously because it can reveal the path of acquisition.

If however both the child and adult really tolerate a mixture of grammars for their language, then the child is really considering two grammars at once. English allows Germanic V-2 in quotation ("Nothing" said John). The child does not know if V-2 is limited to quotation or may have broader application. In fact it also applies to stylistic inversion (in the room ran John). It is therefore no surprise to find brief moments of $\mathrm{V}-2$ productivity for children ("what means that" instead of "what does that mean").

At some point one grammar is defined more broadly and the grammar is linked to specific lexical items. We expect the concept of recursion to help make this distinction. For instance, one can argue that the productive grammar is stated in categorical (V,N,A) rather than non-lexical terms (want, certain), and allows recursive operations (see Roeper, Snyder, and Hiramatsu (2001), (Roeper and Snyder (2003)). Thus recursion is involved not only in determining compositionality, but in grammar choice. In English, V-2 with quotation is linked to certain verbs and disallows any recursion, while in German V-2 applies everywhere and may operate recursively. 
In sum, the child knows that N, NP, or DP are all legitimate projections. Exactly where they will be used in his grammar, and where not, involves a process in which all of these grammar types are maintained (Koster (2000)).

\subsection{THE CONCEPT OF GRAMMAR}

We have argued that the child is overtly maintaining a series of grammar types and must decide which part of his language goes with which grammar type. The term grammar, in this context, seems to say too much, since we are usually referring to a very limited option. As with most scientific enterprises, the vocabulary begins to miss the target as the analysis becomes more refined. We need to abandon the notion of grammar for local concepts in which it is natural for syntax and semantics to operate in concert, where compositionality constrains the acquisition process in a transparent way.

Thanks to Emmon Bach, Manfred Bierwisch Greg Carlson, Bart Hollebrandse, Hans Kamp, Wolfgang Klein, Angelika Kratzer, Irene Krämer, and to the audience in general of the Semantics Meets Acquisition Conference and for comments, to Veerle Van Geenhoven and anonymous reviewers, and for editorial assistance to Casey Hill and Vanessa Cargill. Also my thanks to Jill deVilliers and to the UMass Acquisition Lab members for comments. The perspectives here evolved out of joint work with Jill deVilliers, Ana Perez, Maribel Romero, Jeanine Bock, Lisa Matthewson, Tim Bryant, and Robin Schafer. Mistakes and errors, particularly in my nontechnical exposition of semantic ideas are, obviously, my responsibility.

\section{NOTES}

1 This approach reflects in part the fact that I write primarily from the perspective of acquisition and syntax and therefore the use of the notion of compositionality is rudimentary at this point. ${ }^{2}$ See Categorial grammars (Drozd (1993)), Minimalist approaches (Chomsky (1995, 2001), Roeper (1996).

3 Technically this initial stage in acquisition fails to "converge" in minimalist terms. It is therefore a part of grammar acquisition which deviates slightly from UG, and therefore would be a part of a separate component of LAD.

4 My own work on incorporation has assumed that incorporated nouns are bare heads (Roeper and Siegel (1978), Roeper (1988), Keyser and Roeper (1992), van Hout and Roeper (1999)).

The concept of the First Sister evolved into the Abstract Clitic hypothesis which argued that in order to capture the fact that we generate: homerebuilding and not *rehomebuilding or homeuplifting but *uphomelifting an argument must be moved into a Clitic position that allows only Heads, after a particle has been fronted from that position. The semantic consequences of this could be that there is "type-shifting" or theme-suppression as Dayal (1999) suggests. Empirically the contrast between sentences like:

a. John enjoyed singing at home

b. John enjoyed home-singing 
is that in (b) home is interpreted generically, while in (a) it is controlled by John which we attribute to the distinction between incorporated $\mathrm{N}$ and unincorporated NP (with an anaphor in the Spec position).

Arguments from van Geenhoven about existential properties of incorporated nouns reflect one kind of incorporation, namely phrasal incorporation, which can be seen in English in the following contrast:

a. John saw a quickly-flowing river

b. John saw a quick-flowing river

In (a) an event is implied, but not in (b). The same contrast is found in the difference between nominalizations and compounds:

c. a saver of lives

d. a life-saver

In (c) the event must have transpired, but not in (d).

The arguments in favor of treating incorporated nouns as referential often refer to definite articles in discourse:

e. John enjoyed apple-picking. The apples were beautiful.

Here, however, there is a part-whole relation between the event and the definite article.

Consequently the applies can refer to those still on trees, as well as those actually picked, which means that the incorporated apple could still be a Kind.

In sum, these arguments suggest that the Kind interpretation remains viable. It is clear that Kinds must involve properties in order to be fully specified, but it is less clear that the notion of properties is sufficiently refined to capture the nature of partitioning. (Thanks to E. Bach, G. Carlson for discussion.)

${ }^{5}$ Their responses to presupposition-violation sentences like "Do you want more soup?" when they had none was often "what soup?" and therefore their acceptance of definites does not reflect a failure to recognize presupposition violation.

${ }^{6}$ In general, a variety of further NP nodes could be warranted under the strict view that these semantic differences lead to differences in how these elements are labeled. Schmitt and Munn (2000) argue in depth for language particular variation pivoting around the interaction of AgrP and NumP, showing that variation within Romance responds to these nodes. Hoekstra and

Hyams (1999) and Schafer and deVilliers (2000) argue for a NumP node in acquisition as an explanation for both early phases of root infinitives and DP's.

Our analysis tends in the direction of Chomsky (1998), Collins (2001), Cinque (1999) and the Categorial Grammar traditon where the labels are much more refined (see Drozd (1993)). The ultimate claim is that we have Bare Phrase structure with no labels but rather a bundle of properties. The crucial issue in that case is whether the label itself functions in a further rule, such as a barrier to extraction.

7 Schaeffer (2001) argues that SLI children who use the bare Noun have the cognitive

requirements for definite articles but do not use them. We would argue that in both the normal and SLI cases, children prefer a more economical structure without a DP node which is accomplished by using just the bare noun. A more interesting question is whether it is just an $\mathrm{NP}$ or an $\mathrm{N}$.

8 “[...] categories lacking interpretable features should be disallowed. [...] The argument carries over to other cases, among them semantically null determiners $\mathrm{D}_{\text {null. }}$ If true $\mathrm{D}$ relates to referentiality/specificity in some sense, then an indefinite nonspecific nominal phrase (a lot of people, someone) that enters into scopal interactions must be a pure NP, not DP with null D." (Chomsky, November 1998:55).

${ }^{9}$ See Roeper (2000) for numerous further examples.

${ }^{10}$ See Roeper (2000), deVilliers and Roeper (1995), Perez and Roeper (1999).

${ }_{11}$ See Romero and Bock (2001) for a formulation of truth conditions for temporal nouns in terms of a tripartite structure.

${ }^{12}$ Not only are there expletive determiners, possible forms of Agreement, but as mentioned above complex aspects of Point of View can be linked to the DP (Hollebrandse (2000), 
deVilliers (1999) Speas (2000) and Tenny (1997). For instance, a Speaker POV is involved in a sentence like:

i) John thought the new hat was old.

It is the Speaker who knows that the hat is new. Therefore it is sensible that the child, unsure of what the Determiner the carries, would wait until a narrow, particular-language appropriate form appears.

${ }^{13}$ An interesting hypothesis by Chierchia (1998a,b) has been advanced. He claims that there is a parameter such that a Definiteness feature is attached to Bare Nouns in Asian languages where there are no articles. If one combines that view with a notion of economy of structure, then his view would also predict that English children might pass through a Chinese phase. Crucially, we predict that Chinese children will not project an invented piece of morphology to represent a Determiner, thereby passing through an English phase. Bottari et al (1993) have in fact provided evidence that Italian children spontaneously project a schwa in the position of a Determiner. We suspect this would not be a direct projection of UG, but a version of a Determiner that they have heard and begun to project.

${ }^{14}$ It is possible, as Brun and Avrutin (2001) argue, that movement can impose specificity, which makes the child's task even more complex.

\section{REFERENCES}

Baauw, S. Grammatical Features and the Acquisition of Reference. Ph.D. dissertation, Utrecht. Lot 30, Utrecht, 2000.

Blumenfeld, A. Acquisition of Compounds and Home. Ms. Haverford,1999.

Bottari, P, P. Cipriani, and A.M. Chilosi. "Protosyntactic Devices in the acquisition of Italian morphology." Language Acquisition 3 1993: 285-315.

Burns, Tracy, and Soja, Nancy. "The role of determiner in the interpretation of NP-type nouns." In Elizabeth Hughes, Mary Hughes, and Annabel Greenhill (eds.), BUCLD 21 Proceedings, volume 1. Somerville, MA: Cascadilla Press, 1997: 45-55.

Brun , D. and S. Avrutin. "The Expression of Specificity in a language without Determiners." In Anna H.-J, L. Dominguez, and A. Johansen (eds.) BUCLD 25 Proceedings, volume 1.

Somerville, MA: Cascadilla Press, 2001: 70-81.

Chierchia, G. "Plurality of Mass Nouns and the Notion semantic parameter." in S. Rothstein ed. Events in Grammar. Kluwer, Dordrecht, 1998: 53-103.

Chierchia, G. "Reference to Kinds across Natural Languages." Natural Language Semantics 6. 1998: 339-405.

Chomsky, N. Reflections on Language. New York: Pantheon Books, 1976.

Chomsky, N. Minimalist Inquiries. Cambridge, MA: MIT Press, 1998.

Chomsky, N. Beyond Explanatory Adequacy. Ms. Cambridge, MA: MIT, 2001.

Chomsky The Logical Structure of Linguistic Theory. Plenum Press, 1955/1978.

Chomsky. The Minimalist Program. Cambridge, MA: MIT Press, 1995.

Cinque, C. "Adverbs and Functional Heads: A cross-linguistic Perspective.” Oxford University Press. 1999.

Collins, C. Local Economy. Cambridge, MA: MIT Press, 1997.

Collins, C. Eliminating Labels. MIT WPL 20: 2001.

Crain, S. and R. Thornton. Investigations in Universal Grammar. Cambridge, MA: MIT Press, 1998.

Dayal, V. Bare NP's, Reference to Kinds, and Incorporation. SALT IX 1999.

de Hoop, Helen. Case Configuration and Noun Phrase Interpretation. Ph.D. dissertation, University of Groningen, Grodil 4: 1992.

deVilliers, Jill and Thomas Roeper. "Barriers, binding and acquisition of the NP/DP distinction.” Language Acquisition 4 1995: 73-104. 
deVilliers, J. "On Acquiring the Structural Representations for False Complements." In. B. Hollebrandse (ed.) New Perspectives in Language Acquisition. GLSA Amherst, MA, 1997.

Drozd, K. A Unification Categorial Grammar of Child English Negation. Ph.D. Dissertation, University of Arizona, 1993

Eisenbeiss, S.. "The Acquisition of the Determiner Phrase in German Child Language." in eds. J. Friedemann and L. Rizzi The Acquisition of Syntax. Longman 2000: 26-63.

Heim, I. The Semantics of Definite and Indefinite Noun Phrases. Ph.D. dissertation, University of Massachusetts, Amherst, 1982. N.Y.: Garland, 1988.

Heim, I. and A. Kratzer. Semantics and Generative Grammar. Blackwell, Oxford, 1998.

Hollebrandse, B. The Acquisition of Sequence of Tense. University of Massachusetts at Amherst Linguistics Department, Dissertation, 2000.

Hoekstra, T. and N. Hyams.. "The Eventivity Constraint and Modal Reference Effects in Root Infinitives." in A. Greenhill, H. Littlefield, and C. Tano (eds.) BUCLD 23 Proceedings, volume 1. Somerville, MA: Cascadilla Press, 1999: 240-252.

Hyams, N. "The Underspecification of Functional Categories in Early Grammar." in H. Clahsen Generative Perspectives on Language Acquisition. John Benjamins Publishing, 1996: 91129.

Jackendoff, Ray, Maling, Joan, and Zaenen, Annie. "Home is subject to Principle A.” Linguistic Inquiry 24 1993: 173-177.

Keyser, S.J. and Roeper, T. "Re: The Abstract Clitic Hypothesis.” Linguistic Inquiry 23 1992: 89-125.

Koster, J. "Pied-Piping and the word orders of English and Dutch." In M. Hirotani, Acoetzee, and J,-Y. Kim (eds.) NELS 30, GLSA 2000: 415-426.

Krämer , I. "Interpreting Indefinites: an experimental study of children's language comprehension MPI" Dissertation Series, 2000.

Leonard, L. Eva-Kristina Salameh and Kristina Hansson. Noun Phrase Morphology in Swedish-Speaking Children with Specific Language Impairment. ms. Purdue, 2001.

Longobardi, Giuseppe. "Reference and proper names.” Linguistic Inquiry 25 1994: 609665.

McNamara, J. Names for Things. MIT Press.

Marinis. T. The Acquisition of the DP in Modern Greek. Dissertation Potsdam, Germany, 2000.

Matthewson, L. and J. Schaeffer. "Grammar and pragmatics in the acquisition of article systems." In J. Gilkerson, M. Becker and N. Hyams (eds.). "Language Development and Breakdown 1", UCLA Working Papers in Linguistics No. 5 2000: 1-39.

Matthewson, Lisa. Determiner Systems and Quantificational Strategies: Evidence From Salish. The Hague: Holland Academic Graphics, 1998.

Matthewson, L. T. Bryant, and T. Roeper. "A SALISH Stage in the Acquisition of the English Determiner: Unfamiliar "Definites"” in Proceedings of the SULA Conference, Amherst, Mass. GLSA, 2001

Maratsos, M. "The Use of Definite and Indefinite Reference in Young Children.” Cambridge: Cambridge University Press, 1974.

Matsuo, A. and N. Duffield. "VP-ellipsis and anaphora in first and second language acquisition." Language Acquisition, To appear.

Montague, R. Formal Philosophy: Selected Papers of Richard Montague. Yale University Press, 1974.

Moore, D. The Acquisition of Comparatives. Dissertation, University of Massachusetts at Amherst, (in prep).

Morzyki, M. Mediated Modification: Functional Structure and the Interpretation of Modifier Position. Dissertation, University of Massachusetts at Amhest, 2003.

Musan, R. On the temporal interpretation of nounphrases. Dissertation, MIT, 1995

Namiki, T. "Heads and subheads of compounds." In S. Chiba (ed.) Synchronic and Diachronic Approaches to Language: A Festschrift for Toshio Nakao on the Occasion of his Sixtieth Birthday. Tokyo: Liber Press, 1994. 
Penner, Z. "The Ban on Parameter-resetting, Default Mechanisms, and the Acquisition of V2 in Bernese Swiss German.” In ed. J. Meisel The Acquisition of Verb Placement. Kluwer (1992): 245-283.

Pérez-Leroux, A. and T. Roeper. "Scope and the structure of bare nominals: Evidence from child language." Linguistics 37 (1999): 927-960.

Roeper T. and D. Siegel. "A Lexical Transformation for verbal compounds.” Linguistic Inquiry 9 (1978): 199-260

Roeper, T. "The Role of Universals in the Acquisition of Gerunds." Language Acquisition: the state of the art. eds. E. Wanner and L. Gleitman. Cambridge, MA, (1982): 267-287.

Roeper,T. "Compound Syntax and Head Movement." Yearbook of Morphology 1 (1987): 200-228, Dordrecht: Foris.

Roeper, T. “Universal Bilingualism.” Bilingualism: Langauge and Cognition 2 (1999).

Roeper, T. "Multiple Grammars, Feature-Attraction, Pied-Piping and the Question: Is AGR inside TP?" in ed. N. Müller (In)Vulnerable Grammars in Multilingualism. John Benjamins Publishing (2003): 355-361.

Roeper, T. "Leftward Movement in Morphology." Papers on Morphology and Syntax. V. Lin, C. Krause, B. Breuning, and K. Arregi (eds.), (2000): 35-66.

Roeper, T. and W.Snyder. The Learnability of Language and Recursion. Umass/Uconn ms, 2003.

Roeper,T. W. Snyder, and K. Hiamatsu. "Learnability in a Minimalist Framework: Root Compounds, Merger, and the Syntax-Morphology Interface." Proceedings of Gala ed. I. Lasser Peter Lang (2001): 25-37.

Romero, M. and J. Bock. "Temporal Noun phrase interpretation and theory of mind." in Symposium: Language Acquisition, point of view, and possible worlds. J. deVilliers ed. Proceedings of the VIIIth International congress for the Study of Child Language (2001)

Schaeffer, J. "Articles in English child language." Presented at the LSA, Los Angeles (1999).

Schaeffer, J. "Pragmatics and SLI." Y. Levy, and J. Schaeffer (eds.). Towards a definition of SLI. Lawrence Erlbaum (2001): 135-151.

Schafer, R. and de Villiers, J. "Imagining articles: What $a$ and the can tell us about the emergence of DPCătherineHowell, Sarah A. Fish, and Thea Keith-Lucas (eds.) Proceedings of the 24th BUCLD, volume 2. Somerville, MA: Cascadilla Press (2000): 609-620.

Schmitt, Cristina, and Munn, Alan. “Against the nominal mapping parameter.” NELS 29 (1999): 339-355.

Schmitt and Munn. "Bare Nominals and the Morpho-syntax of Number." in D. Cresti, T. Satterfield, and C. Tortora (eds.) "Current Issues in Romance Linguistics." John Benjamins (2000).

Snyder, W. Language Acquisition and Language Variation: The Role of Morphology. P.h.D. dissertation, MIT (1995).

Slobin. "Cognitive Prerequisites for the Development of Grammar." in D. Slobin and C. Ferguson Studies of Child Language Development. Holt, Rinehart, and Winston (1973) 175-277.

Speas. Person and Point of View in Navajo Direct Discourse Complements. UMass. ms, 2000.

Tenny, C. Short Distance pronouns, point of view, and the nature of pronominal reference. UMass, Ms, 1997.

Thrainnson, H. "On the non-universality of functional categories." in W. Abraham, S. Epstein, H. Thrainsson, and J-W. Zwart. Minimal Ideas. Benjamins Publishing (1996): 253-281.

Vainikka, A. and M. Young Scholten. "Gradual Development of L2 phrase structure, 2000. van Geenhoven, V. "Semantic aspects of noun incorporation in West Greenlandic." Second Language Research 12 (1996): 7-29.

Yang, C. Knowledge and Learning in Natural Language. Oxford University Press, 2003. 
